\title{
Estudo sobre o uso de plantas medicinais em crianças hospitalizadas da cidade de João Pessoa: riscos e benefícios
}

\author{
A.R. Tôrres ${ }^{1}$, R.A.G. Oliveira ${ }^{l *}$, M.F.F.M Diniz' ${ }^{2}$, E.C. Araújo ${ }^{3}$ \\ ${ }^{1}$ Departamento de Fisiologia e Patologia, Universidade Federal da Paraíba, Campus Universitário, \\ 58051-970, João Pessoa, PB, Brasil, \\ ${ }^{2}$ Departamento de Ciências Farmacêuticas, Universidade Federal da Paraíba, Campus Universitário, \\ 58051-970, João Pessoa, PB, Brasil, \\ ${ }^{3}$ Departamento de Enfermagem, Universidade Federal de Pernambuco, Hospital das Clínicas, \\ 50690-701, Recife, PE, Brasil
}

\begin{abstract}
RESUMO: Trata-se de um estudo com abordagem quantitativa, com o objetivo de investigar o uso de plantas medicinais em crianças na faixa etária de zero a 12 anos internadas no Hospital Infantil Arlinda Marques, da cidade de João Pessoa (PB), entre agosto de 2000 a junho de 2001. Um roteiro de entrevista semi-estruturado foi empregado junto aos 132 acompanhantes das crianças para a obtenção dos dados. Os resultados evidenciaram que as doenças que mais acometeram as crianças foram: 1) pneumonia $(26 \%), 2)$ infecções intestinais $(13 \%), 3)$ anemia $(8 \%), 4)$ afecções renais (7\%). Cerca de $27,3 \%$ dos acompanhantes usaram plantas medicinais em suas crianças antes de procurarem o Serviço Hospitalar e 41,7\% associaram plantas com alguma medicação. Diante destes resultados pode-se concluir que a utilização de plantas medicinais em crianças para o tratamento de doenças possui seus riscos e benefícios que precisam ser avaliados pelos profissionais de saúde.
\end{abstract}

Unitermos: Plantas medicinais, crianças, riscos e benefícios.

\begin{abstract}
Survey on the use medicinal plants in children hospitalized in the city of João Pessoa city: risks and benefits". The aim of this study is to investigate the use of medicinal plants in children of zero to 12 years hospitalized in the "Hospital Infantil Arlinda Marques", City of João Pessoa, State of Paraíba, Brazil between August 2000 and June 2001. For the collection of the data a half-structuralized script interview was applied to 132 children's companions. The results evidenced that the illnesses which mostly affected the children were: 1$)$ pneumonia $(26 \%)$, 2 ) infections of the intestines $(13 \%), 3)$ anemia $(8 \%), 4)$ kidneys illnesses $(7 \%)$. About $27,3 \%$ of the companions had used medicinal plants in the children before going to the hospital service; $41,7 \%$ had associated plants with some medicines. Based on this, it can be concluded that the use of medicinal plants in children for the treatment of illnesses has its risks and benefits that need to be evaluated by health professionals.
\end{abstract}

Keywords: Medicinal plants, children, risks and benefits.

\section{INTRODUÇÃO}

A fitoterapia é uma terapêutica popular milenar. Com o reconhecimento pela Organização Mundial de Saúde (OMS), na Conferência de Alma Ata em 1978, o aproveitamento das plantas medicinais foi ressaltado como parte do Programa Saúde Para Todos no Ano 2000 recomendando-se, inclusive a realização de mais estudos e a propagação do uso das plantas medicinais regionais como uma maneira de diminuir custos dos programas de saúde pública (Yamada, 1998).

A utilização de plantas medicinais nos programas de atenção primária à saúde pode se constituir numa alternativa terapêutica muito útil devido a sua eficácia aliada a um baixo custo operacional, a relativa facilidade para aquisição das plantas e a compatibilidade cultural do programa com a população atendida (Matos, 1994).

$\mathrm{Na}$ cultura nordestina é comum o uso de plantas medicinais na preparação de remédios caseiros para tratar várias enfermidades. Entre as mais utilizadas destacamse: 1) hortelã-da-folha-miúda (Mentha $x$ villosa Huds); 2) romã (Punica granatum L.); 3) melão-de-são caetano (Momordica charantia L.); 4) capim-santo (Cymbopogon citratus Stapf.) e, 5) alecrim-pimenta (Lippia sidoides Cham.) (Medeiros Filho et al., 1997; Diniz et al.,1997, Amorim, 1999).

Em estudos efetuados por Medeiros Filho et al., (1997), realizados em João Pessoa (PB), 36,6\% de lactentes e $35 \%$ de pré-escolares foram tratados com plantas medicinais perfazendo $71,1 \%$; a utilização destas foi referida por $96,7 \%$ das mães entrevistadas e, dentre estas, $2,9 \%$ relataram os possíveis efeitos tóxicos 
ocorridos em crianças na faixa dos três meses aos seis anos: 1) vômitos e sudorese, provocados pela hortelãda-folha-miúda (Mentha $x$ villosa Huds), e o sabugueiro (Sambucus australis Cham e Schlecht); e, 2) diarréia, a associação do mastruz (Chenopodium ambrosioides L.), com o saião (Kalanchoe brasiliensis Camb). Devido a efeitos hepatotóxicos, o mastruz é contra indicado para crianças, salvo com acompanhamento de algum profissional da saúde.

$O$ uso de medicamentos em crianças, principalmente nos bebês, nos quais o metabolismo da droga e a função renal são menos eficientes, podem acarretar efeitos mais intensos. A utilização de chás, de forma indiscriminada, em crianças portadoras de enfermidades hepáticas, renais ou outras doenças, poderá lhes trazer sérias conseqüências para sua saúde se não houver acompanhamento médico (Rang; Dale, 2001). Por outro lado, sabe-se que os remédios e as associações de fármacos usados indiscriminadamente nesta população aumentam-lhes a morbimortalidade devido aos efeitos adversos e toxicidade provocados. Nos Estados Unidos a incidência de efeitos adversos por medicamentos em crianças é de 4,5 a 9,8\%; no Brasil, desconhecem-se estudos semelhantes. A segurança para o uso de plantas medicinais na pediatria precisa ser bem avaliada (Wong, 2003).

Portanto, faz-se necessário esclarecer a população sobre alguns pontos essenciais para o uso racional de plantas medicinais tais como: manipulação, coleta e uso terapêutico; isso deverá ser feito com o propósito de correlacionar os saberes popular $x$ científico para que o profissional de saúde indique a terapêutica a ser usada, principalmente em crianças portadoras de doenças crônicas, a fim de se avaliar os riscos e benefícios (Carriconde et al., 1995; Diniz et al., 1997; Medeiros;
Cabral, 2000).

Considerando todo o exposto, foi definido como objetivo desse estudo investigar os riscos e benefícios do uso de plantas medicinais em crianças na faixa etária de zero a 12 anos internadas no Hospital Infantil Arlinda Marques (HIAM) da cidade de João Pessoa (PB).

\section{MATERIAL E MÉTODOS}

Trata-se de um estudo com abordagem quantitativa, realizado entre agosto de 2000 a junho de 2001 com 132 acompanhantes de crianças na faixa etária de zero a 12 anos internadas no Hospital Público Infantil Arlinda Marques (HIAM) em João Pessoa (PB).

Um roteiro de entrevista semi-estruturado foi empregado para obter as informações sobre o grau de conhecimento dos acompanhantes a respeito das plantas utilizadas antes e depois do diagnóstico clínico, da fonte de obtenção, quem as recomendou bem como do grau de conhecimento sobre riscos e benefícios desta prática.

Vale notar que durante o processo de coleta de dados, conforme os acompanhantes nomeavam as plantas que usaram com as crianças antes da hospitalização foi-lhes apresentado a foto da planta para facilitar a identificação desta e, logo após foram solicitados para trazerem uma amostra a qual foi comparada com as plantas existentes no Programa de Educação Tutorial (PET/Farmácia) da UFPB.

Os participantes foram informados sobre o objetivo e a metodologia utilizada neste estudo; em relação ao tratamento dos dados, após a coleta, os mesmos seriam organizados em freqüências relativas e absoluta, apresentados em quadros, tabelas e figuras, procedendo à discussão com a literatura pertinente e que estes seriam divulgados em periódicos científicos; no que diz respeito

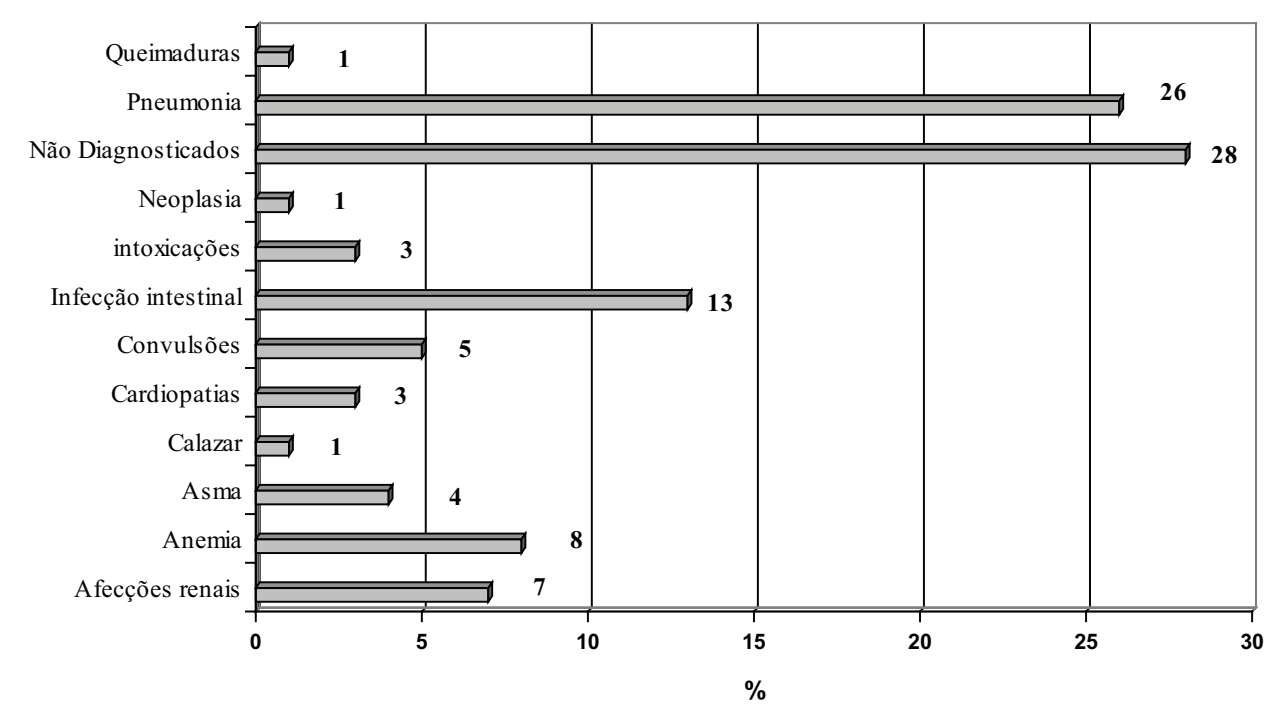

Figura 1. Motivo do internamento das crianças no Hospital Infantil Arlinda Marques no município de João Pessoa (PB). 
à participação de cada um, esta seria voluntária, com a plena liberdade em desistir da pesquisa e recusar a prestar informações durante a coleta de dados, a qual foi iniciada após parecer favorável do Comitê de Ética do Centro de Ciências da Saúde da UFPB. Desta maneira, os princípios da Resolução 196 de 1996 do Conselho Nacional de Saúde, sobre pesquisa com seres humanos, foram respeitados (Brasil, Conselho Nacional de Saúde, 1996).

O banco de dados foi montado para a análise estatística-descritiva, considerando números absolutos e relativos para justificar a maior incidência nas respostas.

\section{RESULTADOS E DISCUSSÃO}

Analisando a figura 1, observam-se as doenças que mais acometeram as crianças foram: 1) pneumonia (26\%), 2) infecções intestinais (13\%),3) anemia (8\%), 4) afecções renais $(7 \%)$. De maneira geral, estes dados demonstram as infecções como alto índice de morbidade, coerente com a situação da saúde na população de baixo nível sócioeconômico. Segundo Medeiros; Cabral (2000), a crescente taxa de natalidade na Região Nordeste, acompanhada de baixa renda e falta ou precárias condições sanitárias podem promover o aparecimento de doenças nas crianças como verminoses, diarréias e infecções respiratórias agudas (IRAs). Enfermidades estas, encontradas menos freqüentemente ou mais facilmente controladas quando se eleva o nível sócio-econômico da população.

Dados deste estudo revelam que $27,3 \%$ dos acompanhantes usaram plantas medicinais em suas crianças antes de procurar o serviço hospitalar. Esta prática pouco cuidadosa no uso de plantas medicinais, devido ao insuficiente conhecimento sobre o assunto ou pela idéia de que "é natural e se bem não fizer, mal não fará", pode causar efeitos indesejados como intoxicações ou ausência da resposta medicamentosa (Medeiros Filho et al., 1997). Alia-se a tudo isto o fato de que $41,7 \%$ associaram plantas com alguma medicação; estas foram do tipo planta $x$ planta ou planta $x$ medicamento, como se observam nos seguintes relatos:

"Usei o lambedor da cebola-branca e beterraba com um remédio de farmácia...."

"Usei um lambedor que minha mãe fez, mas não sei qual era as plantas..."

"Dei um banho com colônia e dei AAS infantil pra tratar a febre dele...."

"Eu dava chá de boldo ou de goiabeira com Imosec pra parar a diarréia...."

Estas associações são perigosas e podem trazer tanto efeitos benéficos quanto maléficos (Wong; Castro, 2003). No intuito de se prevenir intoxicações, diminuição do efeito medicamentoso esperado e, também, de melhorar a identificação da espécie responsável pelo efeito benéfico, no caso de interações planta $x$ planta, os profissionais de saúde não recomendam esta prática.

Estudos realizados por outros autores demonstraram o uso de plantas combinadas (Amorim, 1999; Silveira; Jordão, 1992). Cunha et al., (1995), testaram e confirmaram a atividade antimicrobiana de plantas combinadas (Anadenanthrera colubrina (Vell) Brenan var. cebil (Griseb) + Caesalpinia ferrea Mart.).

DeacordocomWong; Castro,(2003), quandodrogas como digoxina, teofilina, ciclosporina, medicamentos antiretrovirais, sedativos, anticoncepcionais, dentre outras, quando são associadas com a Hypericum perforatum $\mathrm{L}$., têm suas biodisponibilidades diminuídas e que ocorre indução de mania em pacientes que fazem uso de antidepressivos com o Panax ginseng C.A.Meyer .

Estudos de Ameer; Weintraub (1997), destacam que a espécie Citrus $x$ paradisi Macf. interage com medicamentos tipo antagonistas de cálcio e benzodiazepinas (midazolam, triazolam), alterando suas biodisponibilidades. Em outro estudo desenvolvido por Henderson et al., (2000), os flavonóides de Humulus lupulus L. demonstraram forte e seletiva atividade em inibir o citocromo P450 humano, envolvido no metabolismo de drogas. A literatura sobre interações com plantas é escassa. Segundo trabalho realizado por Figueiredo et al., (2000), de 105 plantas selecionadas pelo levantamento bibliográfico, apenas $23,8 \%$ possuem dados sobre interação medicamentosa.

Dentre outros exemplos de interação temos a Lippia alba (Mill) N. E. Brown que potencializa o efeito do pentobarbital, o Eucalyptus globulus Labil que não deve ser administrado junto a sedativos, analgésicos ou anestésicos, pois podem potencializar os efeitos dos mesmos, o Persea americana Mill., que interage com a warfarina na terapia anticoagulante, diminuindo o efeito da droga.

Wong; Castro (2003) consideraram as associações como um grande problema enfrentado pelos profissionais de saúde. Como exemplo, Piper methysticum Forst que apresenta interações com diversos medicamentos, potencializando os efeitos dos benzodiazepínicos e aumentando os efeitos hepatotóxicos do álcool. Outro exemplo citado por estes autores é o Ginkgo biloba L. que pode causar hemorragias em uso concomitante com warfarina ou ácido acetilsalicílico.

Observa-se no quadro III as associações do tipo planta $x$ planta; é prudente, sempre que possível, evitálas.

Cerca $58,4 \%$ dos profissionais da saúde não foram informados a respeito do uso de plantas medicinais em seus pacientes pediátricos, dificultando assim, a sua contribuição na avaliação dos riscos e benefícios que esta prática pode ocasionar. As transcrições citadas a seguir refletem alguns dos motivos pelos quais os acompanhantes não informaram ao profissional sobre a utilização de plantas medicinais:

importante..."

"Eu não informei ao médico porque não achei 
Quadro 1. Distribuição das plantas medicinais de acordo com o número de citações pelos acompanhantes das crianças internadas no Hospital Infantil Arlinda Marques no município de João Pessoa (PB).

\begin{tabular}{|c|c|c|c|}
\hline Nome popular & Nome científico & Família & $\begin{array}{l}\mathrm{N}^{\mathrm{o}} \text { de } \\
\text { citações }\end{array}$ \\
\hline Alho* & Allium sativum L. & Liliaceae & 1 \\
\hline Abacate & Persea americana Mill. & Lauraceae & 1 \\
\hline Anador & Artemisia vulgaris L. & $\begin{array}{l}\text { Asteraceae } \\
\text { (Compositae) }\end{array}$ & 1 \\
\hline Alecrim* & Rosmarinus officinalis $\mathrm{L}$. & $\begin{array}{l}\text { Lamiaceae } \\
\text { (Labiatae) }\end{array}$ & 1 \\
\hline Boldo & Peumus boldus Molina. & Monimiaceae & 5 \\
\hline Beterraba* & Beta vulgaris L. & Chenopodiaceae & 2 \\
\hline Canela & Cinnamomum verum J. Presi. & Lauraceae & 4 \\
\hline Capim-santo & Cymbopogon citratus Stapf. & $\begin{array}{l}\text { Poaceae } \\
\text { (Gramineae) }\end{array}$ & 2 \\
\hline Carambola & Averrhoa carambola $\mathrm{L}$. & Oxalidaceae & 3 \\
\hline Camomila & Chamomilla recutita $\mathrm{L}$. & $\begin{array}{l}\text { Asteraceae } \\
\text { (Compositae) }\end{array}$ & 1 \\
\hline Chambá* & Justicia pectoralis Jacq. & Acanthaceae & 2 \\
\hline Chuchu & Sechium edule Swartz & Curcubitaceae & 1 \\
\hline Cebola-branca* & Allium cepa $\mathrm{L}$. & Liliaceae & 5 \\
\hline Colônia** & Alpinia speciosa Schum. & Zingiberaceae & 5 \\
\hline Erva-cidreira & Lippia alba (Mill) N. E. Brown. & Verbenaceae & 3 \\
\hline Erva-doce & Pimpinella anisum L. & Umbelifera & 4 \\
\hline Estrela-da-noite & Datura sp. & Solanaceae & 1 \\
\hline Eucalipto** & Eucalyptus sp. & Myrtaceae & 3 \\
\hline Espinho-de-cigano* & Acanthospermum hispidum DC & $\begin{array}{l}\text { Asteraceae } \\
\text { (Compositae) }\end{array}$ & 2 \\
\hline Goiabeira & Psidium guajava $\mathrm{L}$. & Myrtaceae & 4 \\
\hline $\begin{array}{l}\text { Hortelã-da-folha- } \\
\text { grande** }\end{array}$ & $\begin{array}{l}\text { Plectranthus amboinicus (Lour) } \\
\text { Spreng. }\end{array}$ & $\begin{array}{l}\text { Lamiaceae } \\
\text { (Labiatae) }\end{array}$ & 8 \\
\hline Limão* & Citrus limonium Risso. & Rutaceae & 1 \\
\hline Louro & Ocimun $\mathrm{sp}$. & $\begin{array}{l}\text { Lamiaceae } \\
\text { (Labiatae) }\end{array}$ & 1 \\
\hline Mastruz** & Chenopodium ambrosioides L. & Chenopodiaceae & 5 \\
\hline Melancia & Citrillus vulgaris Schrad. & Curcubitaceae & 1 \\
\hline Quebra-pedra & Phyllanthus sp. & Euphorbiaceae & 1 \\
\hline Sabugueiro** & Sambucus australis Cham. et Schlecht. & Caprifoliaceae & 4 \\
\hline Saião* & Kalanchoe brasiliensis Camb. & Crassulaceae & 3 \\
\hline
\end{tabular}

* Plantas usadas em associação

** Plantas usadas tanto isoladamente como associadas acredita..."

"Não informei porque ele não perguntou..."

"Não informei porque o médico não

Segundo Oliveira et al., (1998), os profissionais de saúde têm interesse em adquirir conhecimentos sobre plantas medicinais; em um de seus estudos, 51 profissionais foram entrevistados quanto ao uso de plantas medicinais e destes, 98\% concordaram que os profissionais devem conhecer melhor o uso de plantas 
medicinais e $68 \%$ acreditaram que a pouca utilização das plantas na terapêutica é devido à falta de conhecimento nesta área tanto do profissional de saúde quanto dos pacientes.

O quadro II evidencia as plantas mais utilizadas em crianças; muitas têm ação farmacológica comprovada cientificamente e as informações a respeito destas, com respaldo científico, podem ser de grande valia para os profissionais da saúde, podendo lhes orientar quanto ao uso correto, doses recomendadas e, principalmente, sobre contra-indicações e toxicidades, em pacientes pediátricos, inclusive.

As espécies citadas pelos entrevistados, em sua maioria, são coerentes com os dados obtidos em estudos anteriores (Medeiros Filho et al., 1997), e foram utilizadas para tratar, principalmente, dor abdominal e febre. Segundo os acompanhantes $26 \%$ das crianças foram diagnosticadas com pneumonia.

A pneumonia, geralmente causada por bactérias ou vírus, foi responsável por $26 \%$ dos internamentos. Entre os sintomas destacam-se: a febre e a dificuldade respiratória (King, 1998). Através do quadro I podem ser observadas algumas das plantas citadas antes do diagnóstico clínico, quais sejam: 1) colônia (Alpinia speciosa Schum.), 2) cebola-branca (Allium cepa L.), 3) alho (Allium sativum L.), 4) mastruz (Chenopodium ambrosioides L.), 5) hortelã-da-folha-grande (Plectranthus amboinicus (Lour.) Spreng.), 6) eucalipto (Eucalyptus globulus Labil) e, 7) espinho-de-cigano (Acanthospermum hispidum DC.).

A Alpinia speciosa Schum. possui propriedades hipotensoras e sedativas e deve ser usada com cautela em crianças. E pode provocar dermatite de contato em pessoas hipersensíveis, por isso o uso de vaporizador com colônia no quarto para facilitar o descongestionamento nasal é o mais indicado. $\mathrm{O}$ uso como antipirético é coerente com estudos realizados por outros autores (Matos, 1994; Diniz et al., 1997; Amorim, 1999; Silveira; Jordão, 1992).

Allium cepa L., possui propriedades antimicrobianas, hipolipemiante, antitrombótica, antitumoral, hipoglicemiante e antialérgica em patologia bronquial. Entre os compostos com atividade broncodilatadora destacam-se: os isotiocianatos, os quais in vitro inibem as enzimas 5-lipoxigenase e a cicloxigenase. $\mathrm{O}$ extrato etanólico tem demonstrado atividade broncodilatadora em humanos. A cebola poderia ser usada como coadjuvante terapêutico (Alonso, 1998; Bara;Vaneti, 1997/1998).

Allium sativum L., entre as suas propriedades terapêuticas destacam-se hipolipemiante, antiplaquetário, antitumoral e antiinfeccioso (Alonso, 1998). Quanto a sua ação antiinfecciosa apresenta algumas vantagens em relação aos antibióticos sintéticos: 1) pode seradministrado durante mais tempo sem medo de reações adversas, 2) seu emprego não resulta em cepas resistentes, 3) não afeta a flora intestinal e, 4) apresenta atividade antiviral (Alonso, 1998). O uso do alho poderia ser incentivado pelos profissionais de saúde como terapia complementar, pois crianças teriam sido beneficiadas após tratamento.

O Chenopodium ambrosioides L. apesar de ser amplamente usado na medicina popular para o tratamento de pneumonia, poderá trazer riscos às crianças, pois o óleo essencial em altas doses pode provocar náuseas, vômitos, depressão respiratória, lesões hepáticas e renais, transtornos visuais, convulsões, coma e insuficiência cardio-respiratória. É totalmente contra-indicado em crianças abaixo dos três anos (Alonso, 1998). Neste estudo constatou-se o uso numa criança de um ano e sete meses.

Plectranthus amboinicus (Lour.) Spreng. é a planta utilizada no combate às bronquites. No óleo essencial encontram-se o timol e carvacrol com propriedades antimicrobianas, podendo contribuir para a melhora nas patologias do trato respiratório (Matos, 1994). A mucilagem das folhas parece exercer ação protetora das mucosas inflamadas, auxiliando a expectoração. Portanto, seu uso é coerente (Carriconde et al., 1995; Matos, 1994).

A principal atividade do eucalipto (Eucalyptus globulus Labil) é no aparelho respiratório em função do óleo essencial, o qual tem demonstrado, tanto por via oral como inalatória, atividade expectorante, fluidificante e antisséptica da secreção brônquica (Simões et al.,1999). Seu composto mais ativo é o eucaliptol. Qualquer que seja a via de administração, a eliminação predominante é por via pulmonar, justificando assim seu emprego nas afecções respiratórias (Alonso, 1998). Doses altas poderão ocasionar náuseas, vômitos, hematúria, convulsões, depressão bulbar, depressão respiratória e até o coma. Em crianças asmáticas pode ocorrer um efeito paradoxal, broncoespasmo. Uma dose superior a $5 \mathrm{ml}$ do óleo essencial por via interna pode ser fatal (Alonso, 1998).

As estatísticas do Hospital de Melbourne, entre 1981 a 1992, com 109 crianças intoxicadas por ingestão do óleo de eucalipto revelaram que $59 \%$ destas apresentaram sintomas preocupantes: perda da consciência $(28 \%)$, sonolência (27\%), vômitos (37\%), ataxia (15\%), e transtornos respiratórios (11\%), (Alonso, 1998). Apesar de o uso coerente pelos entrevistados, esta planta só deveria ser usada sob prescrição de um profissional da área da saúde. Ela é contra-indicada em crianças abaixo dos dois anos de idade.

Acanthospermum hispidum DC é usado como broncodilatador e comercializado com o nome de asmaflora. Estudos realizados por Maciel et al., (1997), comprovaram o efeito broncodilatador, podendo ser usado como terapia complementar no tratamento de pneumonia.

O Peumus boldus Molina, possui propriedades hepatoprotetora e colerética devido ao alcalóide boldina (Schulz et al., 2001). Segundo dados da literatura, o boldo, devido à presença de alcalóides, somente deveria ser usado em crianças a partir dos seis anos de idade. Foi detectado que o óleo essencial na dose de $0,07 \mathrm{~g} / \mathrm{k}$, produz 


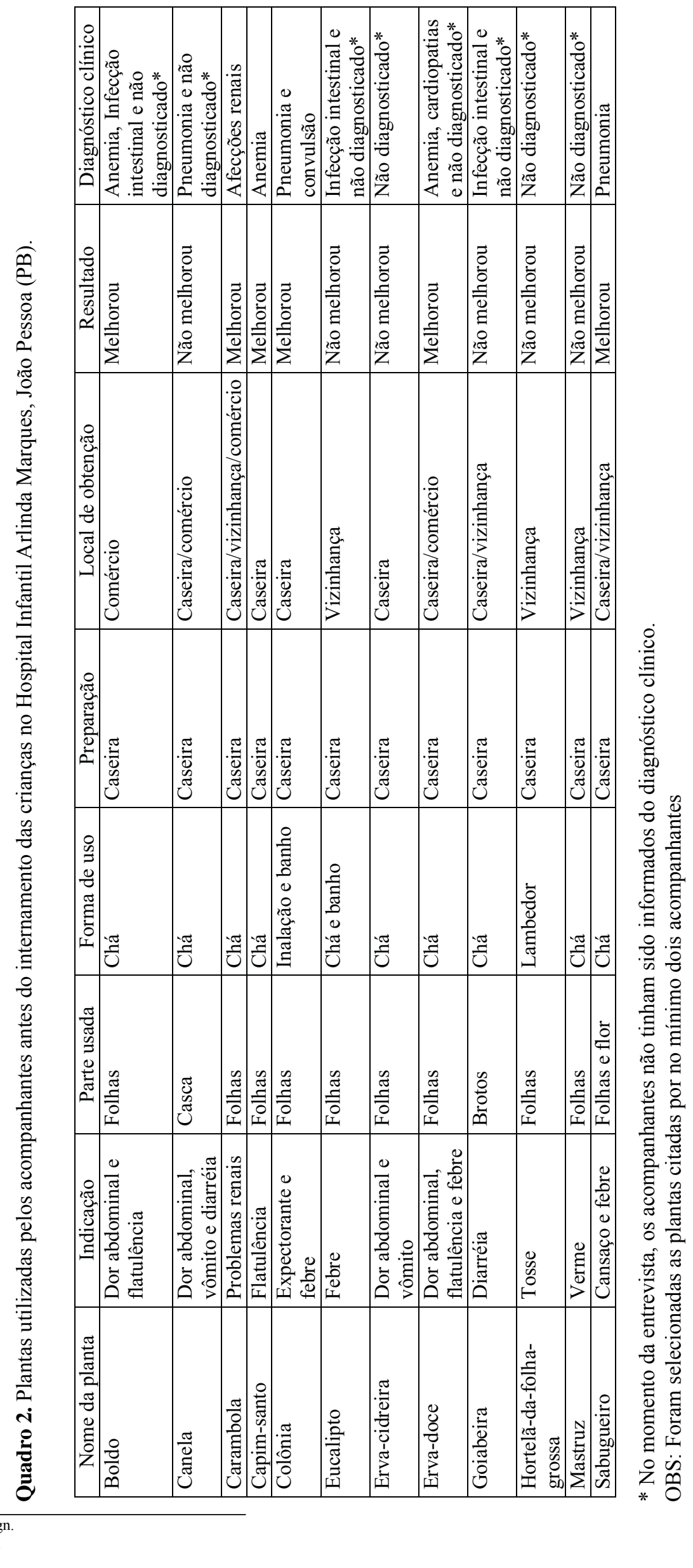


Quadro 3. Associações de plantas medicinais usadas pelos acompanhantes antes do internamento das crianças no Hospital Infantil Arlinda Marques, João Pessoa (PB).

\begin{tabular}{|c|c|c|c|c|c|}
\hline \multicolumn{6}{|c|}{ Associações de plantas no preparo de lambedores } \\
\hline Plantas associadas & Parte usada & Idade & Indicação & Resultado & Diagnóstico Clínico \\
\hline $\begin{array}{l}\text { Hortelã-grande } \\
\text { Mastruz } \\
\text { Cebola-branca } \\
\text { Beterraba }\end{array}$ & $\begin{array}{l}\text { Folhas } \\
\text { Folhas } \\
\text { Bulbo } \\
\text { Tubérculo }\end{array}$ & $\begin{array}{c}2 \text { anos e } \\
6 \text { meses }\end{array}$ & Catarro & Não melhorou & Pneumonia \\
\hline $\begin{array}{l}\text { Hortelã-grande } \\
\text { Mastruz } \\
\text { Saião } \\
\text { Chambá }\end{array}$ & $\begin{array}{l}\text { Folhas } \\
\text { Folhas } \\
\text { Folhas } \\
\text { Folhas }\end{array}$ & 1 ano & Gripe & Melhorou & Pneumonia \\
\hline $\begin{array}{l}\text { Hortelã-grande } \\
\text { Mastruz } \\
\text { Cebola-branca } \\
\text { Colônia } \\
\text { Sabugueiro } \\
\text { Espinho-de-cigano }\end{array}$ & $\begin{array}{l}\text { Folhas } \\
\text { Folhas } \\
\text { Bulbo } \\
\text { Folhas } \\
\text { Flor } \\
\text { Raiz }\end{array}$ & 1.a e $4 . \mathrm{m}$ & Tosse e catarro & Melhorou & Pneumonia \\
\hline $\begin{array}{l}\text { Hortelã-grande } \\
\text { Cebola-branca } \\
\text { Alho } \\
\text { Chambá }\end{array}$ & $\begin{array}{l}\text { Folhas } \\
\text { Bulbo } \\
\text { Bulbo } \\
\text { Folhas }\end{array}$ & 4 anos & Tosse e catarro & Não melhorou & Pneumonia \\
\hline $\begin{array}{l}\text { Mastruz } \\
\text { Alecrim } \\
\text { Hortelã-grande } \\
\text { Saião } \\
\text { Espinho-de-cigano } \\
\text { Cebola branca }\end{array}$ & $\begin{array}{l}\text { Folhas } \\
\text { Folhas } \\
\text { Folhas } \\
\text { Folhas } \\
\text { Raiz } \\
\text { Bulbo }\end{array}$ & $\begin{array}{l}3 \text { anos } \\
6 \text { anos }\end{array}$ & Verme & $\begin{array}{l}\text { Melhorou } \\
\text { Não melhorou }\end{array}$ & 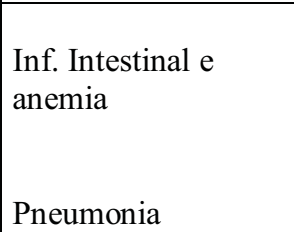 \\
\hline $\begin{array}{l}\text { Cebola-branca } \\
\text { Beterraba }\end{array}$ & $\begin{array}{l}\text { Bulbo } \\
\text { Tubérculo } \\
\end{array}$ & 6 meses & Catarro & Não melhorou & Pneumonia e asma \\
\hline $\begin{array}{l}\text { Eucalipto } \\
\text { Sabugueiro } \\
\text { Colônia }\end{array}$ & $\begin{array}{l}\text { Folhas } \\
\text { Folhas } \\
\text { Folhas }\end{array}$ & 1 ano & Febre & Não melhorou & Pneumonia e anemia \\
\hline $\begin{array}{l}\text { Limão } \\
\text { Hortelã-grande }\end{array}$ & $\begin{array}{l}\text { Fruto } \\
\text { Folhas }\end{array}$ & 1 ano & Tosse & Não melhorou & Pneumonia e anemia \\
\hline $\begin{array}{l}\text { Hortelã-grande } \\
\text { Saião }\end{array}$ & $\begin{array}{l}\text { Folhas } \\
\text { Folhas }\end{array}$ & $\begin{array}{l}1 \text { mês e } \\
1 \text { semana }\end{array}$ & Tosse & Não melhorou & Pneumonia \\
\hline
\end{tabular}

convulsões em animais; portanto, não deve ser utilizado em crianças com história de convulsões (Alonso, 1998). Entre os entrevistados constatou-se o uso numa criança de dois anos.

Estudos científicos revelaram que Kalanchoe brasiliensis Camb., possui ação antiinflamatória e analgésica e efeitos contra bactérias, devido à presença de briofilina (Silva; Oliveira, 1994). Cunha et al., (1995) detectaram na Kalanchoe brasiliensis Camb., atividade bactericida e fungicida.

O extrato bruto das folhas de Lippia alba (Mill) N.E. Brown, possui componentes químicos com propriedades antiespasmódica e sedativa. Diniz et al., (1997), confirmam a ação anti-séptica da erva cidreira contra bactérias $\mathrm{G}+$ que causam infecções respiratórias (Carriconde et al., 1995; Pessini et al., 2003).

Diante desses resultados conclui-se que a utilização de plantas medicinais em crianças possui riscos e benefícios que deveriam levar os profissionais de saúde a adotarem, como prática profissional, a reforçar na anamnese, a investigação de seu uso. Há dados na literatura que podem subsidiar os profissionais na relação com o paciente, referentes à utilização de plantas no tratamento de várias doenças, contribuindo cientificamente na avaliação dos riscos e benefícios desta prática. Por outro lado, sabe-se que poucos profissionais de saúde se preocupam em documentar as informações colhidas através dos pacientes.

\section{AGRADECIMENTOS}

À direção do Hospital Infantil Arlinda Marques, pela autorização concedida para a realização deste estudo. Aos acompanhantes das crianças hospitalizadas, pelas ricas e sábias informações, possibilitando-nos este estudo. A pediatra Prof ${ }^{a}$. Maria do Socorro Sousa, pelas sugestões e apoio. Ao agrônomo Fernando Antônio Cavalcante Viana, pela coleta das plantas medicinais. 
Ao PET-Farmácia, pelo apoio recebido. Ao PIBIC/ $\mathrm{CNPq}$, pela bolsa concedida. Ao bacharel em Ciências da Computação Rafael Guerra Pessoa de Oliveira, pelo apoio técnico na área de informática.

\section{REFERÊNCIAS}

Alonso JR 1998. Tratado de fitomedicina: bases clínicas y farmacológicas. ISIS. Ediciones SRL, p.238-254.

Ameer B, Weintraub RA 1997. Drug interactions with grapefruit joice. Clin Pharmacokinet 33: 103-121.

Amorim JA 1999. Fitoterapia popular e saúde da comunidade: diagnóstico para proposta de integração nos serviços de saúde, em Campina Grande, Paraíba. São Paulo, 206p. Tese de Doutorado - Faculdade de Saúde Pública, Universidade de São Paulo.

Bara MTF, Vanetti MCD 1997/1998. Estudo da atividade antibacteriana de plantas medicinais, aromáticas e corantes naturais. Rev Bras Farmacogn 7/8: 21-34.

Brasil Conselho Nacional de Saúde. Resolução n ${ }^{\circ} 196$, de 10 de outubro de 1996. Dispõe sobre diretrizes e normas regulamentadoras de pesquisa envolvendo seres humanos. Brasília, 1996. 18p.

Carriconde C, Mores D, Fritschen MV, Cardozo Júnior EL 1995. Plantas medicinais \& plantas alimentícias. Olinda: Centro Nordestino de Medicina Popular. Universidade Federal Rural de Pernambuco.

Cunha GMA, Maia AAB, Neri EDR, Nogueira, NAP, Matos, FJA 1995. Atividade antimicrobiana de plantas popularmente usadas no Ceará. Rev Bras Farm 76: 5-6.

Diniz MFFM, Oliveira RAG, Medeiros, ACD, Malta Júnior A 1997. Memento fitoterápico: as plantas como alternativa terapêtica, conhecimentos populares e científicos. João Pessoa: Ed. Universitária.

Figueirêdo CAV, Carvalho ACB, Lima MRL, Assis MR, Batista LM, Oliveira RAG, Diniz, MFFM 2000. Plantas medicinais \& interações medicamentosas. In: Simpósio de Plantas Medicinais do Brasil, Recife, Brasil.

Henderson MC, Miranda CL, Stevens JF, Deinzer ML, Buhler $\mathrm{DR}, 2000$. In vitro innibition of human $\mathrm{P} 450$ enzymes by prenylated flavonoids from hops, Humulus lupulus. Xenobiotica. 30: 235-251.

King M 1998. Atenção primária para a criança: manual do pessoal de saúde. São Paulo: Paulinas.

Maciel SS, Paulo MQ, Sousa CO 1997. Efeito broncodilatador do Acanthospermum hispidum DC, nos doentes pulmonares obstrutivos crônicos (DPOC). Revista Brasileira de Ciências da Saúde 1: 23-30.

Matos FJ 1994. Farmácias vivas: sistema de utilização de plantas medicinais projetado para pequenas comunidades. 2ed. Fortaleza: EUFC.

Medeiros LCM, Cabral IE 2000. As plantas medicinais no cuidar da infância: um guia teórico-prático. Teresina: EDUPI.

Oliveira KRA, Diniz MFFM, Oliveira RAG 1998. A fitoterapia no serviço de saúde pública da Paraíba In: Diniz MFFM, Oliveira RAG, Malta Júnior A 1999. Das plantas medicinais aos fitoterápicos: abordagem multidisciplinar. 2.ed. João Pessoa: UFPB/CCS

Medeiros Filho JG, Pires MPC, Freire ACM 1997. Toxicidade de plantas medicinais na terapêutica infantil. Revista Brasileira de Ciências da Saúde 1: 45-52.

Pessini GL, Holetz FB, Sanches NR, Cortez DAG, Dias Filho BP, Nakamura CV 2003. Avaliação da atividade antibacteriana e antifúngica de extratos de plantas utilizados na medicina popular. Rev Bras Farmacogn 13(Supl 1): 21-23.

Rang HP, Dale MM 2001. Farmacologia. 4.ed. Rio de Janeiro: Guanabara Koogan.

Silva MSH, Oliveira RAG 1994. Plantas medicinais na atenção primária a saúde. João Pessoa.

Silveira F, Jordão L 1992. Das raízes à resistência: repensando a medicina popular. Campina Grande: UEPB/ CENTRAC.

Simões CMO, Schenkel EP, Gosmann G, Mello JCP, Mentz LA, Petrovick PR 1999. Farmacognosia: da planta ao medicamento. Porto Alegre:UFSC.

Schulz V, Hansel R, Tyler VE 2001. Fitoterapia racional. Barueri: Avit's Estúdio Gráfico Ltda.

Wong A, Castro EGR 2003. Aspectos toxicológicos dos fitoterápicos. Arquivos Brasileiros de Fitomedicina Cientifica 1: 96-102.

Wong A 2003. Os usos inadequados e os efeitos adversos de medicamentos na prática clínica. Jornal de Pediatria 79: 379-380.

Yamada CSB 1998. Fitoterapia sua história e importância. Racine 50-51.

15(4):out/dez. 2005 